\section{Kastamonu Eğitim Dergisi Kastamonu Education Journal}

Mart 2019 Cilt:27 Sayı:2

kefdergi.kastamonu.edu.tr
Başvuru Tarihi/Received: 19.02 .2018

Kabul Tarihi/Accepted: 25.05.2018

DOI: $10.24106 /$ kefdergi.2716

\title{
Öğretmen Adaylarının Yaşam Boyu Öğrenme Eğilimleri ile Bireysel Yenilikçilik Düzeylerinin İncelenmesi
}

\section{An Investigation of Pre-Service Teachers' Lifelong Learning Tendencies and Their Individual Innovativeness Levels}

\section{Öz}

\author{
Nilgün YENICE', Gizem ALPAK TUNÇ²
}

Bu çalışmanın amacı, öğretmen adaylarının yaşam boyu öğrenme eğilimleri ile bireysel yenilikçilik düzeylerini belirlemek ve aralarındaki ilişkiyi incelemek olarak belirlenmiştir. Betimsel nitelikteki bu çalışmada ilişkisel tarama modelinden yararlanılmıştır. Araştırmanın çalışma grubunu 2017-2018 eğitim öğretim yılında Türkiye'nin batı bölgesinde bulunan bir üniversitenin eğitim fakültesinde öğrenim görmekte olan 819 öğretmen adayı oluşturmuştur. Veri toplama aracı olarak; "Yaşam Boyu Öğrenme Eğilimleri Ölçeği" ve "Bireysel Yenilikçilik Düzeyi Ölçeği" kullanılmıştır. Verilerin analizinde betimsel istatistiklerden yararlanıımıştır. Betimsel istatistiklere ek olarak, öğretmen adaylarının yaşam boyu öğrenme eğilimleri ile bireysel yenilikçilik düzeyleri arasındaki ilişkiyi belirlemek için; Sperman Brown Sıra Farkları Korelâsyonu kullanılmıştır. Çalışmanın sonucunda, öğretmen adaylarının yaşam boyu öğrenme eğilimlerinin yüksek olduğu buna karşın bireysel yenilikçilik düzeylerinin düşük olduğu tespit edilmiştir. Bununla birlikte, öğretmen adaylarının yaşam boyu öğrenme eğilimleri ile bireysel yenilikçilik düzeyleri toplam puanları arasında anlamlı bir ilişki olmadığı; alt boyut puanları incelendiğinde ise anlamlı ilişkilerin olduğu sonucuna ulaşılmıştır. Elde edilen bulgular doğrultusunda bazı önerilere yer verilmiştir.

\section{Anahtar Kelimeler: Bireysel yenilikçilik, yaşam boyu öğrenme, öğretmen adayları.}

\section{Abstract}

This study aims to analyse the lifelong learning tendencies of pre-service teachers and their individual innovativeness levels. The study was designed as a descriptive research and employed relational model. It was carried out during the 2017-18 academic year among 819 pre-service teachers attending public universities in the western part of Turkey. The study's data were collected using two tools: 1) the lifelong learning scale and 2) the individual innovativeness scale. The data collected were analysed using descriptive statistics. Furthermore, in order to determine the correlation between pre-service teachers' scores on the lifelong learning scale and their scores on the individual innovativeness scale, Sperman-Brown rank order correlation analysis was employed. The findings showed that pre-service teachers had a lifelong learning tendencies was high however their individual innovativeness levels was low. At the same time, there is a meaningless between the pre-service teachers' lifelong learning tendencies and their individual innovativeness levels. For all that sub-dimension scores indicates that there is a meaning relationship between the pre-service teachers' lifelong learning tendencies and their individual innovativeness levels. Based on the findings obtained several suggestions were developed.

Keywords: Individual innovativeness, lifelong learning tendencies, pre-service teachers'. 


\section{Extended Summary}

Purpose: This study aims at revealing the lifelong learning tendencies and individual innovativeness levels of pre-service teachers. It is also aimed at identifying the correlation between the lifelong learning tendencies of the pre-service teachers and their individual innovativeness.

Method: The study was designed as a descriptive research and employed relational model. The participants of this study were 819 pre-service teachers attending a teacher training program at a public university at the western part of Turkey during the academic year of 2017-2018. The grade levels of the participants are as follows: 213 (26\%) pre-service teachers at the first grade, 255 (31.1\%) pre-service teachers at the second grade, 168 (20.5\%) pre-service teachers at the third grade, and $183(22.3 \%)$ pre-service teachers at the fourth grade. Concerning gender there were 424 girls (51.8\%) and 395 (48.2\%) boys participants.

The data of the study were collected using two scales. The first data collection was the scale for the measurement of lifelong learning. The scale was developed by Diker Coşkun (2009). It is consisted of 27 items with a design of 6 point likert scale. The minimum score in the scale is 27 , while the maximum score is 162 . The factor analysis by Diker Coşkun (2009) revealed that the scale included four dimensions. These dimensions are given as follows: motivation, perseverance, self regulation and curiosity. In the original study by Diker Coşkun (2009) the Cronbach alpha realibility coefficient was found to be .89 . In the current study the Cronbach alpha reliability coefficient of the scale was found to be .89 . The other data collection tool used was "the scale of individual innovativeness" which was developed by Hurt, Joseph and Cook (1977). It was adapted into Turkish by Kılıçer and Odabaşı (2010). It is consisted of 20 items with a design of 5 point likert scale. Of twenty items twelve are positively stated while the remaining eight items are negatively stated. The factor analysis by Kilıçer (2011) revealed that the scale included four dimensions. These dimensions are given as follows: resistance to change, thought leadership, openness to experience and risk-taking. In the original study by Hurt, Joseph and Cook (1997) the Cronbach alpha realibility coefficient was found to be .89 . It was found to be .88 for the Turkish version of the scale in the study by Kılıçer and Odabaşı (2010). The Cronbach alpha realibility coefficient of the scale in the present study was found to be .75 .

The data obtained were examined using descriptive statistics. Participants' scores on both scales were examined using the normality test and it was found that the scores were not normally distributed $(p<.05)$. In addition, in order to determine the correlation between pre-service teachers' scores in the scale of lifelong learning and their scores in the individual innovativeness scale the Sperman Brown rank order correlation analysis was employed. The data obtained were not found to distribute normally and therefore, the Sperman Brown correlation analysis was employed (Büyüköztürk, 2017).

Findings:

The findings showed that pre-service teachers have expressed their views on the level of the lifelong learning tendencies at the level of "Very little relevant". It can be said that the lifelong learning tendencies was high because the score obtained from the scale is above the average. The other finding of the study is that it has been determined that $71.06 \%$ of pre service teacher have low level of innovativeness with a mean of $7=50.22$. Based on the scores taken from the scale for the measurement of innovativeness the participants are categorized as follows: those who take the scores of 80 or more are "Innovators", those who take the scores of 69-80 are "Leaders", those who take the scores of 57-68 are "Inquirers", those who take the scores of 46-56 are "Sceptical" and those who take the scores of 46 or less are "Traditionalists" (Kılıçer, 2011). The category of the participants are as follows: $30.52 \%$ are "Inquirers", 27.48\% are "Sceptical", 25.64\% are"Traditionalists", 13.92\% are "Leaders", 2.44\% are "Innovators". Therefore, the participants are in the category of "Inquirers". According to this result, it can be said that pre service teachers have been precaution and cautious towards innovations and have spent a long time thinking about using innovation. At the same time, there is a meaningless between the pre-service teachers' lifelong learning tendencies and their individual innovativeness levels. For all that sub-dimension scores indicates that there is a meaning relationship between the pre-service teachers' lifelong learning tendencies and their individual innovativeness levels. It is conspicuous that in the study, the tendency of pre service teacher to lifelong learning is high while the level of individual innovation is low. Despite the fact that pre service teachers have a tendency to lifelong learning, it may be thought that they are cautious in adopting innovations and practicing them in their lives. Based on the findings obtained several suggestions were developed:

- Given that most of the pre service teachers are at the category of inquirer can be considered a sign of their skeptical and negative attitudes toward the innovations. It may be advisable to carry out various studies which can reveal the causes of negative approaches. 


\section{Giriş}

Bilim ve teknoloji alanında büyük gelişmeler yaşanan günümüzde, gelişmiş bilim ve teknolojiye sahip ülkelerin değişimlerinin oldukça hızlı olduğu görülmektedir. Hızlı bilgi akışının ve değişimin gerçekleştiği bu ülkeler, sahip oldukları bilgi, birikim ve teknolojilerini, onlara sahip olmayan ülkelere pazarlayarak dünya üzerinde hâkimiyetlerini ilan etmektedirler (Yenilmez ve Balbağ, 2016). Bilgiye dayalı bir toplum, fiziksel yeteneklerden çok fikirleri kullanmaya, bilginin tekrarlanmasından çok yeni bilgilerin oluşturulmasına ve teknolojinin kullanımına dayanmaktadır. Bilgi toplumu oluşturma, bireylerin günlük yaşamlarında daha becerili ve bilgili olmalarını gerektirir (A World Bank Report, 2003). Bu ihtiyaçların karşılanabilmesi için bireylerin hayatları boyunca eğitim almaları ve içinde bulundukları topluma ayak uydurmaları gerekmektedir (Güleç, Çelik ve Demirhan, 2012). Bilgi toplumu oluşturma sürecinde, bireylerin 21. yüzyıl becerilerine sahip olmasının önemi yadsınamaz. 21. yüzyılda bireylerin sahip olması gereken özellikler; yaşam boyu öğrenmeyi alışkanlık haline getirme, farklı disiplinlerdeki bilgiye erişme, kullanma, çözümleme ve yapılandırma becerisine sahip olma, karşılaştkları problemlere ilişkin çözüm üretebilme, aynı zamanda yeni ve farklı fikirlere açık ve istekli olma şeklinde tanımlanmaktadır (Partnership for $21^{\text {st }}$ Century Skills, 2010). Bu bireylerin genel olarak bilgiye her koşulda ulaşabilen, yaşam boyu öğrenme alışkanlıklarına sahip, problem çözebilen, yenilik üretebilen kısacası yenilikçilik özellikleri sergileyebilen bireyler olduğu söylenebilir (Rogers, 1995). Bu durum "yaşam boyu öğrenme" ve "bireysel yenilikçilik" kavramlarının bilgi toplumu oluşturmak için kazandırılması gereken önemli özellikler olduğunu ortaya çıkarmaktadır.

\section{Yaşam Boyu Öğrenme}

Yaşam boyu öğrenme kavramı terimsel olarak ilk kez Paul Lengrand tarafindan UNESCO konferansında kullanılmıştır. Bununla birlikte, yetişkin eğitimine odaklanan ilk yaşam boyu öğrenme enstitüleri kurulmuş ve günümüzde Avrupa Birliği (AB) tarafindan sürekli mesleki eğitim sistemi adıyla sistematik bir yapıya dönüştürülmüştür. Daha sonra Lizbon ve Stockholm'de 2000 yılında düzenlenen konsey toplantlarıyla yaşam boyu öğrenme konusu vurgulanmış, OECD (1996) tarafindan da yaşam boyu öğrenmenin, bireylerin bilgi ve yeterliklerini geliştirmek için amaçılı olarak beşikten mezara kadar gerçekleştirdiği tüm öğrenme etkinliklerini kapsadığı belirtilmiştir (Akkuş, 2008; Lightfoot ve Brady, 2005; Nijhof, 2005).

Avrupa Komisyonu (2006), yaşam boyu öğrenmeyi; "bireyin yaşamı boyunca bilgisini, becerilerini, yeterliklerini bireysel, sosyal ya da mesleki olarak geliştirmeyi amaçlayan tüm etkinlikler" olarak tanımlamaktadır. Bununla birlikte Kulich (1982), yaşam boyu öğrenmeyi bireye yaşamları boyunca eğitimin sunulması, White (1998), bireylerin yaşamlarını yönetebilmeleri için gerekli bilgileri edinmesi şeklinde ele almıştr. Demirel (2009) ise, yaşam boyu öğrenmeyi, "Bireyin potansiyelini ve yeterliklerini yaşamı boyunca geliştiren devamlı bir süreçtir" şeklinde tanımlamıştır.

Öğrenmenin belli bir süreyle sınırlandırılmadan yaşam boyunca devam etmesi, yaşama uyum sağlamak ve nitelikli bir birey olmayı sürdürmek açısından önemlidir (Erdamar, 2011). Knapper ve Cropley'e (2000) göre yaşam boyu öğrenme becerisine sahip birey, kendi öğrenme sorumluğunu alarak öğrenmesini planlayan, öğrenme ortamında aktif olan, farklı disiplinlerden elde ettiği bilgiyi bir araya getirip yapılandırabilen ve gerektiğinde farklı öğrenme stratejileri uygulayabilen birey olarak tanımlamaktadır. Akkoyunlu (2008) ise yaşam boyu öğrenen bireyin özelliklerini; meraklı, yeni gelişmelerle ve konularla ilgili, bilgi okuryazarı, örgütleme ve öğrenme becerilerine sahip olma olarak tanımlamıştır. İlgili alan yazın incelendiğinde; yaşam boyu öğrenmenin özellikle motivasyon, sebat, merak ve öğrenmeyi düzenleme gibi bilişsel ve duyuşsal alanlara ilişkilendirildiği görülmektedir. Örneğin; bireylerin davranışlarını harekete geçiren motivasyon, öğrenme sürekliliğinin sağlanmasında önemli bir rol oynamaktadır. De Jesus ve Conboy (2001) çalışmalarında, motive olmuş öğretmenlerin eğitim reformlarının uygulanmasında, öğrencilerin başarı ve doyum sağlamasında ve ortaya çıkan değişimlerin uygulanmasında önemli bir göreve sahip olduklarını belirtmişlerdir. Bireylerin yaşam boyu öğrenme eğilimlerini sürdürebilmelerinin motivasyonun yüksek olması ile sağlanabileceği düşünülebilir. Yaşam boyu öğrenen bireyin bir diğer özelliği "öğrenmede kararlıık halinin devamı” yani sebatkar olmasıdır (Diker Çoşkun, 2009). Öğrenmede bireylerin motivasyonu kadar bu motivasyonu farklı durumlarda sürdürebilmeleri de önemlidir. Sebat, öğrenme sürecinde karşılaşılabilecek her türlü engel ve umutsuzluk karşısında hedefe odaklanabilme ve bunu sürdürme direncini gösterebilme olarak tanımlanır (Derrick, 2003). Yaşam boyu öğrenmeyi sağlayan bir diğer faktör meraktır. Merak, genel olarak bir şeyi anlamak veya öğrenmek için duyulan istek olarak tanımlanabilir (TDK, 2014). Piaget (1952) merakı, bilginin genişlemesi, büyümesi için bir gereklilik olarak görmektedir. Yaşam boyu öğrenme süreci belli bir zaman kısıtlaması olmayan yaşam boyunca devam eden öğrenme sürecidir (Kılıç, 2015). Dolayısıyla yaşam boyu öğrenme sürecinde öğrenmeyi düzenleyebilme oldukça önemlidir. Senemoğlu (2009) öz düzenlemeyi, öğrenme sürecinde bireyin kendi davranışlarını gözlemleyip, onları kendi ölçütlerine göre değerlendirmesi, kontrol etmesi ve yönlendirmesi olarak tanımlamaktadır. Öz düzenleme becerisine sahip bireyler; kendi öğrenme sorumluğunu alabilen, hedeflerini be- 
lirleyen ve hedeflerine ulaşmak için kendine uygun stratejiler geliştirebilen, içinde bulunduğu süreci değerlendirebilen ve bu doğrultuda öz eleştirisini yapabilen, aynı zamanda kendi kendine dönütler verip gerekli değişiklik ve yenilikleri yapabilen bireylerdir (Ozan, Çelik ve Kıncal, 2014).

\section{Bireysel Yenilikçilik}

Yenilikçilik, genel anlamıyla "yenilikçi olma durumu" olarak tanımlanmaktadır (TDK, 2014). Rogers (1995) yenilikçiliği bireyin yeni olan fikirlere kendi bulunduğu sistemin diğer üyelerinden daha önce uyum sağlaması; Hurt, Joseph ve Cook (1977) ise yenilik ve değişmelere olan isteklilik olarak tanımlamıştır. Demirel ve Seçkin (2008) ise yenilikçiliği; "değişmek, risk almak, daha da önemlisi bilinenlerin dışına çıkmayı göze almak" şeklinde ifade etmiştir.

Bireyler sahip oldukları özellikler bakımından, yenilikçilik bağlamında birbirlerinden farklılaşmaktadırlar. Bu farklılaşmalar nedeniyle bireyler herhangi bir yeniliği daha erken veya daha geç benimsemekte, daha fazla veya daha az değişime istekli olmakta ve daha çok veya daha az risk almaktadırlar (Kılıçer ve Odabaşı, 2010). Bu bağlamda araştırmacılar bireylerin yenilikleri nasıl algıladıklarını, yenilikleri benimseme süreçlerindeki farklılıkları ve nedenlerini açıklamaya çaıısmışlardır. Tarde (1903), yeniliklerin yayılması üzerine yaptığı çalışmalar sonucunda yeniliklerin bireyler tarafindan benimsenme yüzdeleri ile zaman arasındaki ilişkisini bir S eğrisinde göstermiştir. S-eğrisinde yenilik öncelikle az sayıda insan tarafindan benimsemekte iken zamanla bu oran artmaktadır. Yeniliklerin benimsenmesine ait yayılım eğrisinin normal dağılıma yakın olması yenilikleri benimseyenlerin standart biçimde kategorize edilmesinin önünü açmıştır. Bununla birlikte; Rogers (1995), toplumun zamana göre yenilikleri benimseme sürecini açıklayan "Yeniliklerin Yayılması" (Diffusion of Innovations) çalışmasını oluşturmuştur. Çalışmasında bireyleri yenilikleri benimseme süreçlerine bağlı olarak ortalama $(X)$ ve standart sapma (SS) gibi istatistiksel teknikler yardımıyla Yenilikçiler, Öncüler, Sorgulayıcılar, Kuşkucular ve Gelenekçiler olmak üzere beş farklı kategoriye ayırmıştır (Rogers, 1995).

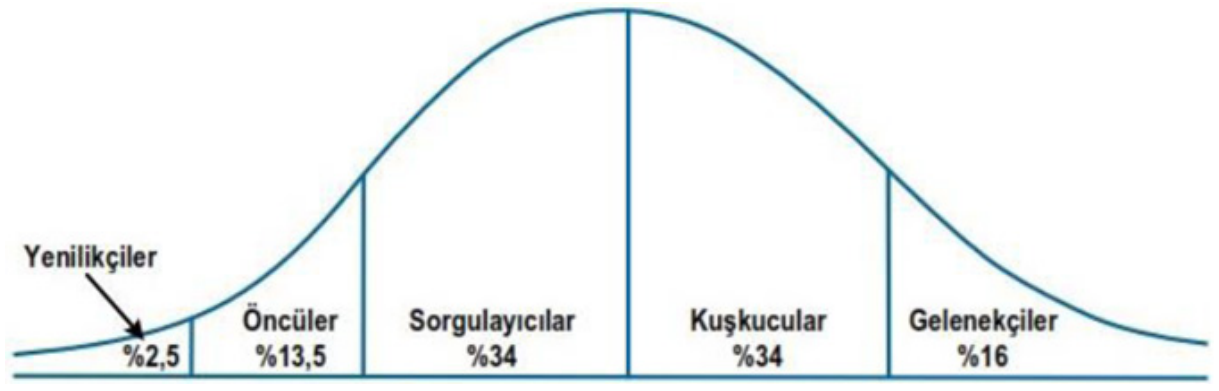

\section{Şekil 1. Bireysel Yenilikçilik Kategorileri (Rogers, 1995).}

Yenilikçiler; risk almayı seven, yeni fikirleri denemekte istekli, girişken, eğitimli, sosyal ağları, iletişim araçlarını ve teknolojiyi kullanabilen, meraklı, güvenilir bilgiye ulaşmak veya yeni uygulamaları denemek için sıkça seyahat eden, bilimsel bilgiye güvenen, üst düzey düşünme becerilerine sahip, sosyal sistemde aktif ve etrafina yardım etmeyi seven bireylerdir. Öncüler; toplumda diğer bireylere yenilikler hakkında yol gösteren, değişim taraftarı, yeniliklere yönelik tutumları ile rol model olan, iletişim araçlarını yoğun bir şekilde kullanan, fikir lideri, vizyon sahibi, teknoloji odaklı, yüksek eğitimli, sosyal bireylerdir. Sorgulayıcılar; yenilikleri benimsemede temkinli davranırlar. Yeni bir fikri benimsemeden önce, onun kendilerine sağlayacakları yararlar hakkında uzun bir düşünme süreci geçirirler. Bu kategorideki bireyler risk alma konusunda fazla hevesli olmayan, ortalama yaş, eğitim ve sosyo-ekonomik düzeye sahiptirler. Kuşkucular; yeniliklere çekingen davranmakta, toplumun çoğunluğunun o yeniliği benimsemesini beklemektedirler. Bu kategorideki bireyler özellikle teknoloji alanındaki yeniliklerinden yararlanmak için dışarından bir yardıma muhtaç olan; eğitim düzeyi kendisinden önce gelen diğer kategorilerdeki bireylere göre daha düşük olan, yaş ortalaması yüksek, sosyal iletişim araçlarına göre kişiler arası iletişimi tercih eden bireylerdir. Gelenekçiler; geleneklerine ve alışkanlıklarına sıkı bir şekilde bağlı olduklarından, yenilikleri benimseme süreçleri çok uzundur. Yeniliklere ve değişimlere karşı önyargılı bir bakış açısına sahiptirler. Yenilikleri benimsemeden önce diğer kategorilerdeki bireylerin onu denemesi ve başarılı sonuçlar almasını beklerler. Bu yüzden çoğu zaman gelenekçiler bir yeniliği benimsediklerinde, diğer kategorideki bireyler başka bir yeniliği benimsemiş ve kullanmaya başlamış olurlar. Gelenekçiler genel olarak teknoloji hakkında çok fazla yardıma gereksinim duyarken, sosyal iletişim ve etkileşimleri çok sınırlıdır. Bundan dolayı yeniliklerle ilgili bilgiyi daha çok güvendikleri bireylerden yüz yüze iletişim yoluyla edinirler (Kılıç, 2015; Kılıçer, 2011; Rogers, 1995).

\section{Yaşam Boyu Öğrenme ve Bireysel Yenilikçilik}

Bilgi toplumunun oluşması ve ülkemizin gelişmesinde; bilim ve teknolojideki değişimleri takip eden yaşamının her anında öğrenen ve yeniliklerin yayılmasına öncü olan bireylerin varlığı oldukça önemlidir. Bu bağlamda; toplumumuzda 
yaşam boyu öğrenme becerisine sahip ve yenilikçi bireylerin oluşması için eğitim programlarında gerçekleşecek revizyonlara büyük bir sorumluluk düşmektedir. Nitekim güncellenen öğretim programlarında, 21. yüzyıl becerileri, yaşam boyu öğrenme ve bireysel yenilikçilik gibi kavramlar önem kazanmıştır (MEB, 2017). Yenilenen öğretim programı ile öğrencilere kazandırılmak istenilen nitelikler güncellenmiştir. Bu durum, öğretme ve öğrenme süreci ile birlikte öğretmenlerin görev ve sorumluluklarının da yenilenmesini gerekli kılmıştır.

İlgili alan yazın incelendiğinde, öğretmen adaylarının yaşam boyu öğrenme becerilerinin (Evin Gencel, 2013; İzci ve Koç, 2012) ve bireysel yenilikçilik düzeylerinin (Kılıçer, 2011; İncik ve Yelken; 2011; Yılmaz, 2013) incelendiği çalışmalara rastlanılmaktadır. Buna karşın; öğretmen adaylarının yaşam boyu öğrenme becerileri ile bireysel yenilikçilik düzeylerinin incelendiği çalışmaya rastlanılamamıştr. İlgili alan yazında öğretmenlerin yaşam boyu öğrenme becerileri ile bireysel yenilikçilik düzeylerinin incelendiği sınırlı sayıda çalışma yer almaktadır (Kılıç, 2015). Kılıç (2015) çalışmasında, ilköğretim branş öğretmenlerinin bireysel yenilikçilik düzeyleri ve yaşam boyu öğrenme eğilimlerini ve aralarındaki ilişkiyi incelemeyi amaçlamıştı. Araştırmada, öğretmenlerin yaşam boyu öğrenme eğilimlerinin yüksek olduğu, yenilikçilik düzeylerinin ise düşük olduğu sonucuna ulaşılmıştr. Bununla birlikte, yaşam boyu öğrenme eğilimi ile bireysel yenilikçilik düzeyi arasında bir ilişki olmadığı ama alt boyutlar arasında anlamlı ilişkilerin var olduğu tespit edilmiştir.

Bilgi toplumunun oluşmasında önemli rol oynayan öğretmenlerin yeniliklere açık, toplumsal gelişmeleri takip eden, kendini sürekli yenileyen ve yaşam boyu öğrenme becerilerine sahip olmaları yetiştirecekleri öğrencilerin de bu becerileri kazanmalarında etkili olmaktadır. Davis ve Sumara (1997) öğretmenlerin öğrenme özelliklerinin içinde bulundukları toplumu etkilemesi bakımından o toplumdan ayrı düşünülemeyeceğini vurgulamaktadır. Öğretmen ve öğretmen adaylarının yaşam boyu öğrenme eğilimine ve bireysel yenilikçiliğe sahip olması, onlara yüklenen "toplumsal değişimi sağlamada aracı olma” rolünü etkili biçimde gerçekleştirmelerini sağlayacaktır (Coolahan, 2002; UNESCO, 1996).

Bu çalışmanın amacı, öğretmen adaylarının yaşam boyu öğrenme eğilimleri ile bireysel yenilikçilik düzeylerini belirlemek ve aralarındaki ilişkiyi incelemek olarak belirlenmiştir. Bu amaç doğrultusunda aşağıdaki alt problemlere yanıt aranmıştır:

1. Öğretmen adaylarının yaşam boyu öğrenme eğilimleri ne düzeydedir?

2. Öğretmen adaylarının bireysel yenilikçilikleri ne düzeydedir?

3. Öğretmen adaylarının yaşam boyu öğrenme eğilimleri ile bireysel yenilikçilik düzeyleri arasında anlamlı bir ilişki var mıdır?

\section{Yöntem}

\section{Araştırma Modeli}

Bu çalışma; Türkiye'nin bat bölgesinde yer alan bir üniversitenin eğitim fakültesinde öğrenim görmekte olan öğretmen adaylarının yaşam boyu öğrenme eğilimleri ile bireysel yenilikçilik düzeylerini belirlemeyi ve aralarındaki ilişkiyi incelemeyi amaçlayan betimsel bir çalışmadır. Bu bağlamda araştırmada ilişkisel tarama modelinden yararlanılmıştır. iliş̧kisel tarama modeli, iki ve daha çok sayıdaki değişken arasında birlikte değişim olup olmadığını, eğer varsa derecesini belirlemeyi amaçlayan araştırma modelidir (Büyüköztürk, 2017).

\section{Çalışma Grubu}

Araştırmanın çalışma grubunu 2017-2018 eğitim öğretim yılında Türkiye'nin bat bölgesinde bulunan bir üniversitenin eğitim fakültesinde öğrenim görmekte olan 819 öğretmen adayı oluşturmuştur. Araştırmanın çalışma grubuna ilişkin bilgiler, Tablo 1'de yer almaktadır.

Tablo 1. Çalışma grubunun demografik özellikleri

\begin{tabular}{llcc}
\hline Değişkenler & Kategori & N & $\%$ \\
\hline \multirow{2}{*}{ Cinsiyet } & Kız & 424 & 51.8 \\
& Erkek & 395 & 48.2 \\
\hline \multirow{3}{*}{ Sınıf düzeyi } & 1. sınıf & 213 & 26.0 \\
& 2.sınıf & 255 & 31.1 \\
& 3.sınıf & 168 & 20.5 \\
& 4.sınıf & 183 & 22.3 \\
\hline
\end{tabular}




\begin{tabular}{llcc}
\hline Değişkenler & Kategori & N & $\%$ \\
\hline & Fen Bilgisi & 143 & 17.5 \\
& Sosyal Bilgiler & 132 & 16.1 \\
& Okul Öncesi & 149 & 18.2 \\
Öğrenim görülen anabilim & PDR & 148 & 18.1 \\
dalı & Müzik Eğitimi & 105 & 12.8 \\
& Sınıf Eğitimi & 81 & 9.9 \\
& BÖTE & 61 & 7.4 \\
\hline
\end{tabular}

Çalışmaya katılan öğretmen adaylarının 424’ü (\% 51.8) kız, 395'i (\%48.2) erkektir. Çalışma grubunun 213'ü (\%26) 1. sınıf, 255'i (\%31.1) 2. sınıf, 168'i (\%20.5) 3. sınıf, 183'ü (\%22.3) 4. sınıfta öğrenim görmektedir.

\section{Veri Toplama Araçları}

Çalışmada, öğretmen adaylarının yaşam boyu öğrenme eğilimlerini belirlemek amacıyla Diker Coşkun (2009) tarafindan geliştirilmiş olan "Yaşam boyu öğrenme eğilimleri ölçeği" kullanılmıştır. Yaşam boyu öğrenme eğilimi ölçeği; $6^{\prime}$ Iı likert tipinde olup, 27 madde ve 4 alt faktörden oluşmaktadır. Ölçeğin, "yaşam boyu öğrenmede motivasyon" ve "sebat" alt boyutları olumlu maddeler içerirken, öğrenmeyi düzenlemede yoksunluk" ve "merak yoksunluğu" alt boyutları ise olumsuz maddeler içermektedir. Ölçekteki olumsuz maddelerden oluşan "öğrenmeyi düzenlemede yoksunluk" ve "merak yoksunluğu" alt boyutundaki maddeler, anlaşılırlığı kolaylaştırmak için ters puanlanmış ve alt boyut isimleri ise "öğrenmeyi düzenleme", "merak" gibi olumlu ifadeler ile değiştirilmiştir. Yaşam boyu öğrenme eğilimleri ölçeğinin "motivasyon" alt boyutu 1, 2, 3, 4, 5, 6. maddeleri içermekte, "sebat" alt boyutu 7, 8, 9, 10, 11, 12. maddeleri, “öğrenmeyi düzenleme" alt boyutu 13, 14, 15, 16, 17, 18. maddeleri, "merak" alt boyutu ise 19, 20, 21, 22, 23, 24, 25, 26 ve 27. maddeleri içermektedir.

Yaşam boyu öğrenme eğilimleri ölçeğinin genel ortalamasında ölçekten alınabilecek minimum puan (27x1) 27 ve maksimum puan (27x6) 162 olarak belirlenmiştir. Diker Coşkun (2009) tarafindan yapılan araştırmada yaşam boyu öğrenme eğilimi ölçeğinin Cronbach alpha güvenirlik katsayısı .89 olarak belirlenmiştir. Bu çalışma için tekrarlanan güvenirlik analizi sonucunda ise, yaşam boyu öğrenme eğilimleri ölçeğinin Cronbach Alfa güvenirlik katsayısı .89 olarak hesaplanmıştr. Ölçeğin alt boyutlarına ilişkin Cronbach Alfa güvenirlik katsayıları sırasıyla motivasyon alt boyutu için .84; sebat alt boyutu için .81; öğrenmeyi düzenleme alt boyutu için .86 ve merak yoksunluğu alt boyutu için .87 olarak bulunmuştur.

Öğretmen adaylarının bireysel yenilikçilik düzeylerini belirlemek için "Bireysel Yenilikçilik Düzeyi Ölçeği” kullanılmıştır. Hurt, Joseph ve Cook (1977) tarafindan geliştirilmiş olan ölçek; Kılıçer ve Odabaşı (2010) tarafindan Türkçeye uyarlanmıştr. Ölçek; $5^{\prime} \mid$ li likert tipinde olup 20 madde ve 4 alt boyuttan oluşmaktadır. Bu alt boyutlar; Değişime direnç $(4,6,7,10,13,15,17$ ve 20. Maddeler), Fikir önderliği (1, 8, 9, 11 ve 12. Maddeler), Deneyime açıklık (2, 3, 5, 14, 18. Maddeler) ve Risk alma (16 ve 19. Maddeler) olarak isimlendirilmiştir. Ölçeği oluşturan maddelerin 12 'si olumlu (1, $2,3,5,8,9,11,12,14,16,18$. ve 19 . maddeler), $8^{\prime} i$ ise olumsuz ifadelerden $(4,6,7,10,13,15,17$. ve 20 . maddeler) oluşmaktadır. Hurt, Joseph ve Cook (1977) tarafindan yapılan çalışmada ölçeğin özgün formuna ilişkin Cronbach Alfa güvenirlilik katsayı .89 olduğu ifade edilirken; Kılıçer ve Odabaşı (2010) tarafından Türkçe'ye uyarlama çalışması sonucunda güvenirlik katsayısı .88 olarak bulunmuştur. Bu çalışma için tekrarlanan güvenirlik analizi sonucunda ise ölçeğin Cronbach Alfa güvenirlik katsayısı .75 olarak hesaplanmıştı. Alt boyutlarına ait güvenirlik katsayıları ise sırasıyla değişime direnç alt boyutu için .79; fikir önderliği alt boyutu için .92; deneyime açıklık alt boyutu için .91 ve risk alma alt boyutu için 79 olarak bulunmuştur.

\section{Veri Çözümleme Teknikleri}

Veri toplama araçlarından elde edilen veriler, betimsel istatistikler (frekans, aritmetik ortalama, standart sapma ve yüzde) kullanılarak analiz edilmiştir.

Çalışmada yararlanılacak istatistiksel yöntemlerin belirlenebilmesi için yaşam boyu öğrenme eğilimleri ölçeği ile bireysel yenilikçilik ölçek puanları için normallik testi yapılmıştır. Kolmogorov-Smirnov testi (Tablo 2) ve De Augusto Pearson değerleri incelendiğinde elde edilen puanların normallik varsayımını karşılamadığı tespit edilmiştir (DP yuör̆renme $=7.26, p=0.03, p<0.05 ; P_{\text {bireyselyenilikçilik }}=8.41, p=0.01, p<0.05$ ). 


\section{Tablo 2. Normallik testi sonucu}

\begin{tabular}{lccc}
\hline & \multicolumn{3}{c}{ Kolmogorov-Smirnov } \\
\cline { 2 - 4 } & İstatistik değeri & $\mathrm{df}$ & $\mathrm{p}$ \\
\hline Yaşam Boyu Öğrenme Eğilimleri Ölçeği & .061 & 819 & .000 \\
Bireysel Yenilikçilik Düzeyleri & .107 & 819 & .000 \\
\hline
\end{tabular}

Araştırmada kullanılan yaşam boyu öğrenme eğilimi ölçeği altılı likert tipli derecelendirme; bireysel yenilikçilik düzeyi ölçeği ise beşli likert tipli derecelendirmeye sahiptir. Araştırma kapsamındaki öğretmenlerin katılım düzeylerini belirlemek amacıyla süreksiz olan ölçekteki cevap seçenekleri, istatistiksel işlemlerle elde edilen sonuçların yorumlanabilmesi için "sürekli" hale getirilmiştir. Süreksiz değişkenleri sürekli hale getirerek puan aralıklarının gerçek sınırını hesaplamak için seçenek sayısı-1/seçenek sayısı formülü kullanılmıştır. Bu doğrultuda altılı likert tipli yaşam boyu öğrenme eğilimi ölçeği ve beşli likert tipi bireysel yenilikçilik düzeyi ölçeğine ait puan aralıkları Tablo 3'de verilmiştir.

\section{Tablo 3. Ölçeklere ilişkin puan aralıkları}

\begin{tabular}{lrll}
\hline \multicolumn{2}{c}{ Yaşam Boyu Öğrenme Eğilimi Ölçeği } & \multicolumn{2}{c}{ Bireysel Yenilikçilik Düzeyi Ölçeği } \\
\hline 1. Hiç uymuyor & $1.00-1.83$ & 1.Kesinlikle katılmıyorum & $1.00-1.80$ \\
2.Kısmen uymuyor & $1.84-2.66$ & 2.Katılmıyorum & $1.81-2.60$ \\
3.Çok az uymuyor & $2.67-3.49$ & 3.Ortadayım & $2.61-3.40$ \\
4.Çok az uyuyor & $3.50-4.32$ & 4. Katılıyorum & $3.41-4.20$ \\
5.Kısmen uyuyor & $4.33-5.15$ & 5.Kesinlikle katılıyorum & $4.21-5.00$ \\
6.Çok uyuyor & $5.16-6.00$ & & \\
\hline
\end{tabular}

Bununla birlikte, ölçek yardımıyla hesaplanan yenilikçilik puanına göre bireylerin genel olarak yenilikçilik düzeyleri değerlendirilebilmekte ve belirlenen puan aralıklarına göre bireyler yenilikçilik bağlamında kategorize edilebilmektedir (Hurt, Joseph ve Cook, 1977). Yenilikçilik puanının hesaplanması işleminin birinci adımında ölçekteki olumlu maddelerin $(1,2,3,5,8,9,11,12,14,16,18$ ve 19) puanları toplanmış ikinci adımda ise, olumsuz maddelerin $(4,6,7,10,13$, 15,17 ve 20) puanları toplanmıştır. Bireysel yenilikçilik puanının hesaplanmasında " 42 + (olumlu maddelerin toplam puanı) - (olumsuz maddelerin toplam puanı)" formülünden yararlanılmıştır. Tablo 4'de bireysel yenilikçilik düzeyi ölçeğine ilişkin ortalama puan aralıklarına göre ilgili düzey ve kategorileri belirtilmiştir.

\section{Tablo 4. Bireysel yenilikçilik ölçeği düzey ve kategoriler}

\begin{tabular}{llc}
\hline Bireysel Yenilikçilik Düzeyi Ölçeği & Ortalama Puan Aralığı \\
\hline \multirow{4}{*}{ Düzeyler } & Yüksek Düzey Yenilikçi & $>68$ \\
& Orta Düzey Yenilikçi & $68-64$ \\
& Düşük Düzey Yenilikçi & $<64$ \\
\hline \multirow{3}{*}{ Kategoriler } & Yenilikçi & $>80$ \\
& Öncü & $69-80$ \\
& Sorgulayıcı & $57-68$ \\
& Kuşkucu & $46-56$ \\
& Geleneksel & $<46$ \\
\hline
\end{tabular}

Tablo 4'e göre katılımcılardan elde edilen toplam puanlar 80 puanın üstündeyse yenilikçi, 69 ve 80 puan arasındaysa öncü, 57 ve 68 puan arasındaysa sorgulayıcı, 46 ve 56 puan arasındaysa kuşkucu, 46 puanın altındaysa gelenekçi olarak kategorize edilmektedir. Aynı zamanda katılımcıların bireysel yenilikçilik puanı 68 'den büyük ise yüksek düzeyde yenilikçi, 68 ile 64 arasında ise orta düzeyde yenilikçi ve 64'den küçük ise düşük düzeyde yenilikçi olarak değerlendirilmiştir (Hurt, Joseph ve Cook, 1977).

Betimsel istatistiklere ek olarak, öğretmen adaylarının yaşam boyu öğrenme eğilimleri ile bireysel yenilikçilik düzeyleri arasındaki ilişkiyi belirlemek için; Sperman Brown Sıra Farkları Korelâsyonu kullanılmıştır. Sperman Brown Sıra Farkları Korelâsyonu normal dağılıma sahip olmayan değişkenler arasındaki ilişkileri betimleme amacıyla başvurulan bir tekniktir (Büyüköztürk, 2017). Sperman Brown Sıra Farkları Korelâsyonu katsayısı değişkenler arasındaki ilişkinin derecesini, bu katsayının işareti (+ veya -) ise ilişkinin yönünü göstermektedir. Sperman Brown Sıra Farkları Korelâsyon katsayısının 1.00 veya 1.00'e yakın olması pozitif bir ilişkiyi; -1.00 veya -1.00'e yakın olması negatif bir iliş̧iyi; 0.00 olması ise bir ilişkinin olmadığını gösterir. Sperman Brown Sıra Farkları Korelâsyon katsayısının büyüklük bakımından yorumlanmasında üzerinde tam olarak ortaklaşılan aralıklar bulunmamakla birlikte, korelasyonu yorumlamada sıklıkla şu 
sınırlar kullanılmaktadır: Korelasyon katsayısının mutlak değer olarak 0.70-1.00 arasında olması yüksek, 0.70-0.30 arasında olması orta; 0.30-0.00 arasında olması ise düşük düzeyde bir ilişki olarak

tanımlanabilir (Büyüköztürk, 2017).

\section{Bulgular}

\section{Birinci Alt Probleme İlişkin Bulgular}

Araştırmanın birinci alt problemi “Öğretmen adaylarının yaşam boyu öğrenme eğilimleri ne düzeydedir?” şeklinde belirtilmiștir. Bu alt probleme cevap aramak için öğretmen adaylarının yaşam boyu öğrenme eğilimleri ölçeğinden aldıkları toplam puanların aritmetik ortalama $(\overline{\mathrm{X}})$, standart sapma (S.S) ve minimum ile maksimum değerleri Tablo 5 'de verilmiştir.

Tablo 5. Yaşam boyu öğrenme eğilimleri ölçeğine ilişkin betimsel istatistikler

\begin{tabular}{lccccc}
\hline Yaşam Boyu Öğrenme Eğilimleri Ölçeği & $\mathrm{N}$ & $\overline{\mathrm{X}}$ & $\mathrm{SS}$ & Min & Max \\
\hline Motivasyon & 819 & 4.22 & 0.93 & 1.33 & 6.00 \\
Sebat & 819 & 4.05 & 0.89 & 1.17 & 6.00 \\
Öğrenmeyi Düzenleme & 819 & 3.79 & 1.11 & 1.00 & 6.00 \\
Merak & 819 & 4.47 & 1.05 & 1.00 & 6.00 \\
Toplam Puan & 819 & 4.17 & 0.69 & 2.63 & 5.96 \\
\hline
\end{tabular}

Tablo 5 incelendiğinde öğretmen adaylarının yaşam boyu öğrenme eğilimi ölçeğinden en düşük alınan puanın (2.63) en yüksek alınan puanın ise (5.96) olduğu, ölçek ortalamasının ( $\bar{X}=4.17)$ olduğu görülmektedir. Başka bir ifade ile öğretmen adayları yaşam boyu öğrenme eğilimi ölçeğinin tümüne 4.17 katılım derecesi ile "Çok az uyuyor" şeklinde görüş bildirmişlerdir. Alt boyutlara ilişkin betimsel istatistikler incelendiğinde ise öğretmen adayları motivasyon ( $\bar{X}=4.22)$, sebat ( $\bar{X}=4.05)$, öğrenmeyi düzenleme ( $\bar{X}=3.79)$ alt boyutlarında "Çok az uyuyor" şeklinde; merak ( $\bar{X}=4.47)$ alt boyutunda ise "Kısmen uyuyor" şeklinde görüşlerini belirtmişlerdir.

\section{íkinci Alt Probleme i̇lişkin Bulgular}

Araştırmanın ikinci alt problemi "Öğretmen adaylarının bireysel yenilikçilikleri ne düzeydedir?" şeklinde belirtilmiştir. Bu alt probleme cevap aramak için öğretmen adaylarının bireysel yenilikçilik ölçeğinden aldıkları toplam puanlar düşük düzey, orta düzey ve yüksek düzey olarak sınıflandırılmış ve elde edilen grupların betimsel istatistikleri Tablo 6 'da verilmiştir. Gruplar sınıflandırıııken, bireysel yenilikçilik puanı 68'den büyük olan öğretmen adayları yüksek düzeyde yenilikçi, 68 ile 64 arasındaysa orta düzeyde yenilikçi ve 64'den küçükse düşük düzeyde yenilikçi değerlendirmesi dikkate alınmıştır (Hurt Joseph ve Cook, 1977).

Tablo 6. Bireysel yenilikçilik düzeylerine ilişkin betimsel istatistikler

\begin{tabular}{lcccccc}
\hline Bireysel Yenilikçilik & $\mathrm{f}$ & $\%$ & $\overline{\mathrm{X}}$ & $\mathrm{SS}$ & Min & Max \\
\hline Yüksek Düzey & 134 & 16.36 & 74.22 & 5.00 & 69.00 & 89.00 \\
Orta Düzey & 103 & 12.58 & 65.52 & 1.38 & 64.00 & 68.00 \\
Düşük Düzey & 582 & 71.06 & 50.22 & 7.05 & 30.00 & 63.00 \\
Toplam Puan & 819 & 100 & 56.07 & 11.37 & 30.00 & 89.00 \\
\hline
\end{tabular}

Tablo 6 incelediğinde öğretmen adaylarının bireysel yenilikçilik puanlarına göre $\% 71.06$ 'sı $\bar{X}=50.22$ puan ortalaması ile düşük düzeyde yenilikçi, \%12.58' i $\bar{X}=65,52$ puan ortalaması ile orta düzeyde yenilikçi ve $\% 16.36$ 'sı $\bar{X}=74.22$ puan ortalaması ile yüksek düzeyde yenilikçi olduğu görülmektedir. Genel olarak incelendiğinde, öğretmen adaylarının düşük düzeyde yenilikçi olduğu ve bireysel yenilikçilik puan ortalamasının $(\bar{X}=56.07)$ düşük düzey yenilikçiliğin sınır değeri olan $\overline{\mathrm{X}}=64$ 'ten aşağıda olduğu görülmektedir.

Öğretmen adaylarının bireysel yenilikçilik ölçeğinden aldıkları toplam puanlar bireysel yenilikçilik kategorilerine göre sınıflandırılmış ve elde edilen grupların betimsel istatistikleri Tablo 7'de verilmiştir. Bireysel yenilikçilik düzeyinde elde edilen toplam puanlara göre öğretmen adaylarının puanları 80 puanın üstündeyse yenilikçi, 69 ve 80 puan arasındaysa öncü, 57 ve 68 puan arasındaysa sorgulayıcı, 46 ve 56 puan arasındaysa kuşkucu, 46 puanın altnndaysa gelenekçi olarak kategorize edilmiştir (Hurt Joseph ve Cook, 1977). 
Tablo 7. Bireysel yenilikçilik kategorilerine ilişkin betimsel istatistikler

\begin{tabular}{lcccccc}
\hline Bireysel Yenilikçilik & $\mathrm{f}$ & $\%$ & $\overline{\mathrm{X}}$ & $\mathrm{SS}$ & Min & Max \\
\hline Yenilikçiler & 20 & 2.44 & 83.80 & 2.48 & 81.00 & 89.00 \\
Öncüler & 114 & 13.92 & 72.54 & 3.06 & 69.00 & 80.00 \\
Sorgulayıcılar & 250 & 30.52 & 62.33 & 3.20 & 57.00 & 68.00 \\
Kuşkucular & 225 & 27.48 & 50.51 & 3.19 & 46.00 & 56.00 \\
Gelenekçiler & 210 & 25.64 & 43.00 & 2.08 & 30.00 & 45.00 \\
Toplam Puan & 819 & 100 & 56.07 & 11.37 & 30.00 & 89.00 \\
\hline
\end{tabular}

Tablo 7 incelendiğinde öğretmen adaylarının çoğunun "Sorgulayıcılar" ( $f=250$; \%30.52), "Kuşkucular" (f=225, \%27.48) ve "Gelenekçiler" ( $f=210 ; \% 25.64)$ kategorileri içinde yer aldığı görülmektedir. Bununla birlikte "Yenilikçiler" ( $f=20 ; \% 2.44$ ) ve "Öncüler" ( $f=114 ; \% 13.92)$ kategorilerinde az sayıda öğretmen adayının yer aldığı tespit edilmiştir.

Tablo 8'de öğretmen adaylarının bireysel yenilikçilik ölçeğinin alt boyut ve toplam puanlarına ilişkin betimsel istatistik değerlerine yer verilmiştir. Ölçekteki olumsuz maddelerden oluşan "değişime direnç" alt boyutundaki maddeler ise anlaşılırlığı kolaylaştırmak için ters puanlanmıştır.

Tablo 8. Bireysel yenilikçilik düzeyleri ölçeğine ilişkin betimsel istatistikler

\begin{tabular}{lccccc}
\hline Bireysel Yenilikçilik & $\mathrm{N}$ & $\overline{\mathrm{X}}$ & SS & Min & Max \\
\hline Değişime Direnç & 819 & 3.59 & 0.77 & 1.38 & 5.00 \\
Fikir Önderliği & 819 & 2.74 & 1.22 & 1.00 & 5.00 \\
Deneyime Açıklık & 819 & 2.90 & 1.29 & 1.00 & 5.00 \\
Risk Alma & 819 & 2.61 & 1.26 & 1.00 & 5.00 \\
Toplam Puan & 819 & 3.10 & 0.56 & 1.80 & 4.75 \\
\hline
\end{tabular}

Tablo 8 incelendiğinde öğretmen adaylarının Bireysel Yenilikçilik Düzey ölçeğinin toplam puan ortalaması $(\overline{\mathrm{X}}=3.10)$ ile "Ortadayım" şeklinde görüş bildirmişlerdir. Alt boyutlara ilişkin istatistikler incelendiğinde ise öğretmen adaylarının Değişime Direnç alt boyutunda ( $\bar{X}=3.59)$ "Katlıyorum", Fikir Önderliği ( $\bar{X}=2.74)$, Deneyime Açıklık $(\bar{X}=2.90)$ ve Risk alma $(\bar{X}=2.61)$ alt boyutlarında "Ortadayım" şeklinde görüşlerini belirtmişlerdir.

\section{Üçüncü Alt Probleme İlişkin Bulgular}

Araştrrmanın üçüncü alt problemi "Öğretmen adaylarının yaşam boyu öğrenme eğilimleri ile bireysel yenilikçilik düzeyleri arasında anlamlı bir ilişki var mıdır?" şeklinde belirtilmiştir. Öğretmen adaylarının yaşam boyu öğrenme eğilimleri ile bireysel yenilikçilik düzeyleri arasındaki ilişkiyi belirlemek amacıyla yapılan Sperman Brown Sıra Farkları Korelâsyonu sonuçları Tablo 9'da sunulmaktadır.

Tablo 9. Sperman brown sıra farkları korelâsyonu sonuçları

\begin{tabular}{|c|c|c|c|c|c|c|c|}
\hline & & & & & ysel Yenilikçilik & & \\
\hline & & & Değişime Direnç & Fikir Önderliği & Deneyime Açıklık & Risk Alma & Toplam puan \\
\hline & Mativacyon & $r$ & $.144^{*}$ & $.120^{*}$ & $.144 *$ & $.083 *$ & $.145^{*}$ \\
\hline & IVIotivasyon & $p$ & .000 & .001 & .000 & .018 & .000 \\
\hline$\underline{\xi}$ & Cohat & $r$ & $-.136 *$ & $-.154^{*}$ & $-.136 *$ & $-.186^{*}$ & $-.131^{*}$ \\
\hline$\frac{\bar{\omega}}{50}$ & sepat & $p$ & .000 & .000 & .000 & .000 & .000 \\
\hline $\int_{0}^{2}$ & Öğrenmeyi & $r$ & $.359 *$ & $.365^{*}$ & $.359 *$ & $.314^{*}$ & $.382 *$ \\
\hline ठิ & düzenleme & $p$ & .000 & .000 & .000 & .000 & .000 \\
\hline ⿷匚 & Merat & $r$ & $-.476^{*}$ & $-.495^{*}$ & $-.476^{*}$ & $-.475^{*}$ & $-.401 *$ \\
\hline 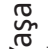 & IVlerak & $p$ & .000 & .000 & .000 & .000 & .000 \\
\hline & Tonlam & $r$ & $-.118^{*}$ & $-.139 *$ & $-.118^{*}$ & $-.176^{*}$ & -.064 \\
\hline & IOplam & $\mathrm{p}$ & .001 & .000 & .001 & .000 & .065 \\
\hline
\end{tabular}

Tablo 9 incelendiğinde öğretmen adaylarının yaşam boyu öğrenme eğilimleri ile bireysel yenilikçilik düzeyleri toplam puanları arasında anlamlı bir ilişki görülmemektedir ( $r=-.064, p>.05)$. Buna karşın, yaşam boyu öğrenme eğilimleri ölçeği motivasyon alt boyutu ile bireysel yenilikçilik düzeyleri ölçeği tüm alt boyut ve toplam puanları arasında düşük düzeyde, pozitif ve anlamlı bir ilişki olduğu görülmektedir ( $r=.144, p<.05 ; r=.120, p<.05 ; r=.144, p<.05 ; r=.083, p<.05$; 
$r=.145, p<.05)$. Elde edilen bu bulgu ile yaşam boyu öğrenmeye yönelik motivasyonu artan bireylerin bireysel yenilikçilik düzeylerinin de arttğı sonucuna ulaşılmaktadır. Öğretmen adaylarının yaşam boyu öğrenme eğilimleri ölçeği sebat alt boyutu ile bireysel yenilikçilik düzeyleri ölçeği tüm alt boyut ve toplam puanları arasında düşük düzeyde, negatif ve anlamlı bir ilişki olduğu belirlenmiştir ( $r=-.136, p<.05 ; r=-.154, p<.05 ; r=-.136, p<.05 ; r=-.186, p<.05 ; r=-.131, p<.05)$. Elde edilen bu bulgu ile yaşam boyu öğrenme eğilimine sebat düzeyi yüksek olan öğretmen adaylarının bireysel yenilikçilik düzeylerinin düşük olduğu görülmektedir. Öğretmen adaylarının yaşam boyu öğrenme eğilimleri ölçeği öğrenmeyi düzenleme alt boyutu ile bireysel yenilikçilik düzeyleri ölçeği tüm alt boyut ve toplam puanları arasında orta düzeyde, pozitif ve anlamlı bir ilişki olduğu görülmektedir ( $r=.359, p<.05 ; r=.365, p<.05 ; r=.359, p<.05 ; r=.314, p<.05 ; r=.382$, $p<.05)$. Yaşam boyu öğrenme eğilimleri ölçeği merak alt boyutu ile bireysel yenilikçilik düzeyleri ölçeği tüm alt boyut ve toplam puanları arasında ise orta düzeyde, negatif ve anlamlı bir ilişki olduğu belirlenmiştir $(r=-.476, p<.05 ; r=-.495$, $p<.05 ; r=-.476, p<.05 ; r=-.475, p<.05 ; r=-.401, p<.05)$.

\section{Sonuçlar}

Bu bölümde araştırma sonuçlarının yorumu ve tartışması yapılmıştır. Bu çalışmanın temel amacı, öğretmen adaylarının yaşam boyu öğrenme eğilimleri ile bireysel yenilikçilik düzeylerini incelemek ve aralarındaki ilişkiyi belirlemektir. Bu amaçla, elde edilen araştırma bulguları çalışmanın alt problemlerine bağlı olarak aşağıda belirtilen başlıklar altında tartşıımıştır.

\section{Öğretmen adaylarının yaşam boyu öğrenme eğilimlerinin belirlenmesi}

Öğretmen adaylarının yaşam boyu öğrenme eğilimlerinin genel olarak ne düzeyde olduğunu belirlemek amacıyla yapılan analizlerin sonucuna göre, toplam puanların ortalaması $\bar{X}=4.17$ 'dir. Öğretmen adayları ölçekte yer alan maddelerin kendileri için uygunluğuna ilişkin, "Çok az uyuyor" düzeyinde görüş bildirmişlerdir. Ölçekten elde edilen puanın ortalamanın üzerinde olmasından dolayı yaşam boyu öğrenme eğilimlerinin yüksek olduğu söylenebilir.

İlgili alan yazın incelendiğinde, farklı örneklemler üzerinde uygulanmış yaşam boyu öğrenme eğilimlerinin incelendiği çalışmalara rastlanılmaktadır (Kılıç, 2015; Şahin ve Arcagök, 2014; Yavuz Konokman ve Yanpar Yelken, 2014). Kılıç (2015) çalışmasında; öğretmenlerin yaşam boyu öğrenme eğilimleri ölçeği maddelerine "Kısmen Uyuyor" düzeyinde görüş bildirdikleri sonucuna ulaşmıştır. Bununla birlikte elde edilen toplam puanların ölçek ortalamasının üzerinde olduğundan öğretmenlerin yaşam boyu öğrenme eğilimlerinin yüksek olduğunu tespit etmiştir. Şahin ve Arcagök (2014) çalışmalarında öğretmenlerin yaşam boyu öğrenme yeterlilik düzeyinin yüksek olduğu sonucunu elde etmişlerdir. Bununla birlikte, Yavuz Konokman ve Yanpar Yelken'in (2014) eğitim fakültesi öğretim elemanlarının yaşam boyu öğrenme yeterliklerine ilişkin algılarına yönelik çalışmasında da öğretim elemanlarının yaşam boyu öğrenme yeterliklerinin yüksek olduğu belirlenmiştir.

Yaşam boyu öğrenme eğilimi ölçeğinin alt boyutları incelendiğinde ise öğretmen adaylarının motivasyon, sebat ve öğrenmeyi düzenleme alt boyutlarında "Çok az uyuyor" şeklinde; merak alt boyutunda ise "Kısmen uyuyor" şeklinde görüşlerini belirtmişlerdir. Bu durum ile öğretmen adaylarının her bir alt boyutta ortalama puanın üzerinde bir derecede katılım gösterdiği sonucuna ulaşımaktadır. Öğretmen adaylarının yaşam boyu öğrenme motivasyonlarının yüksek olması, yaşam boyu öğrenmeye istekli ve meraklı olması, yaşam boyu öğrenme faaliyetlerini sürdürme eğiliminde olması ve bu süreçte kendi öğrenme sorumluluklarını alarak zamanını ve imkanlarını düzenleyebilmesi, yaşam boyu öğrenme eğilimlerinin yüksek olmasını sağlamaktadır. Bu durum öğretmenlerin yaşam boyu öğrenmeye ilişkin olumlu bir bakış açısına sahip oldukları biçiminde yorumlanabilir. İlgili alan yazındaki araştırmaların sonucu da bu durumla benzerlik göstermektedir. Örneğin; Kılıç (2015), yaşam boyu öğrenme eğilimi ölçeğinin alt boyutlarını incelendiğinde, öğretmenlerin motivasyon alt boyutuna ilişkin katlım düzeyinin "Çok uyuyor"; Sebat alt boyutuna ilişkin kathlım düzeyinin "Kısmen Uyuyor", öğrenmeyi düzenlemede yoksunluk alt boyutunun katlım düzeyinin "Kısmen Uymuyor" ve merak yoksunluğu alt boyutunun katılım düzeyinin ise "Kısmen Uymuyor" şeklinde olduğu sonucuna ulaşmıştır. İzci ve Koç (2012) öğretmen adaylarının yaşam boyu öğrenmeye ilişkin görüşlerini değerlendirdikleri çalışmalarında, öğretmen adaylarının yaşam boyu öğrenme konusunda güçlü bir duyarlığa sahip olduklarını tespit etmişlerdir. Bununla birlikte, Evin Gencel (2013) öğretmen adaylarının kendilerini yaşam boyu öğrenmede "yeterli" algıladıkları sonucuna ulaşmıştır.

\section{Öğretmen adaylarının bireysel yenilikçilik düzeylerinin belirlenmesi}

Çalışma sonucunda öğretmen adaylarının bireysel yenilikçilik düzeyi açısından $\% 71.06$ 'sının $\not X=50.22$ puan ortalaması ile düşük düzeyde yenilikçi olduğu belirlenmiştir. Bireysel yenilikçilik kategorileri dikkate alındığında ise öğretmen adaylarının \%30.52'sinin Sorgulayıcı, \%27.48'inin Kuşkucu, \%25.64'ünün ise Gelenekçi olduğu sonucuna ulaşılmıştr. Buna karşın öğretmen adaylarının yalnızca \%13.92'si Öncü, \%2.44'ü ise Yenilikçi kategorisinde yer alabilmiştir. Elde 
edilen bu sonuca göre, öğretmen adaylarının yeniliklere karşı temkinli ve tedbirli davrandıkları, yeniliği kullanmak için uzun süre düşünme süreci yaşadıkları söylenebilir. Bu bulgunun ortaya çıkmasında eğitim sistemimizde ve öğretim programlarının uygulama sürecinde yaşanan değişimlerin etkili olduğu söylenebilir. Yapılan değişimlerin çok kısa bir süre içinde hayata geçmesi ile öğretmen adaylarının yenilikleri ve değişimleri benimsemekte ve uygulamakta yetersiz kaldıkları düşünülebilir. Öğretmen adaylarının yenilikleri benimsemekte ve uygulamaktaki sorgulayıcı tavırları, sık ve kısa sürede gerçekleşen değişim ve yeniliklerin amacına ulaşmasını engelleyen bir faktör olarak düşünülebilir. Illgili alan yazın incelendiğinde benzer çalışma sonuçlarına rastlanılmaktadır (Çuhadar, Bülbül ve Ilgaz, 2013; Kert ve Tekdal, 2012; Kılıç, 2015; Kılıçer, 2011; İncik ve Yelken, 2011; Timuçin, 2009; Ünal, 2014; Yılmaz, 2013). Örneğin; İncik ve Yelken (2011), yapmış oldukları çalışmada öğretmen adaylarının sorgulayıcılar kategorisinde yer aldıklarını tespit etmiştir. Aynı şekilde Kılıçer (2011) çalışmasında öğretmen adaylarının sorgulayııı kategoride yığıldıklarını bulmuştur. Yılmaz (2013) çalışmasında okul öncesi öğretmen adaylarının yarısından fazlasının düşük yenilikçilik düzeyine sahip olduğu sonucuna ulaşmıştır. Kılıç (2015), öğretmenlerin düşük düzeyde yenilikçi olduğunu tespit etmiştir. Buna karşın; öğretmen ya da öğretmen adaylarının yüksek düzeyde yenilikçi olduğu bulgusuna sahip çeşitli araştırmalara da rastlanılmaktadır (Köroğlu, 2014; Özgür, 2013; Yılmaz Öztürk ve Summak, 2014).

Bireysel yenilikçilik düzeyi ölçeğinin alt boyutları incelendiğinde; öğretmen adaylarının Değişime Direnç alt boyutunda "Katlıyorum"; Fikir Önderliği, Deneyime Açıklık ve Risk Alma alt boyutları ve toplam puan ortalamalarının ise "Ortadayım" aralığına denk geldiği tespit edilmiştir. Bu durum, öğretmen adaylarının yenilikleri denemeye istekli fakat yenilikleri denerken yaşayabilecekleri çeşitli risklere karşı şüpheci; yeniliklerin getirdiği değişimlere uyum sağlamada ise temkinli olduklarını göstermektedir. Elde edilen bu bulgu, alan yazında yer alan öğretmen ve öğretmen adayları ile gerçekleştirilen çeşitli çalışmaların sonuçları ile benzerlik göstermektedir (Akın Kösterelioğlu ve Demir, 2014; Çuhadar, Bülbül ve Ilgaz 2013; Kılıçer, 2011; Kılıç, 2015; Özgür, 2013). Kılıç (2015), bireysel yenilikçilik ölçeği maddelerine öğretmen adaylarının "Ortadayım" düzeyinde görüş bildirdiği sonucuna ulaşmıştır.

\section{Öğretmen adaylarının yaşam boyu öğrenme eğilimleri ile bireysel yenilikçilik düzeyleri arasındaki ilişki}

Öğretmen adaylarının yaşam boyu öğrenme eğilimleri ile bireysel yenilikçilik düzeyleri arasında anlamlı bir ilişkinin olup olmadığını belirlemek amacıyla yapılan korelasyon analizi sonucunda, anlamlı bir ilişki olmadığı sonucuna ulaşılmıştr. Çalışmada öğretmen adaylarının yaşam boyu öğrenme eğilimleri yüksek çıkarken bireysel yenilikçilik düzeylerinin düşük çıkması dikkat çekmektedir. Bu durumun, öğretmen adaylarının yaşam boyu öğrenme eğilimine sahip olmalarına rağmen; yenilikleri benimseme ve onları hayatlarında uygulama konusunda temkinli davranmalarından kaynaklandığı düşünülebilir.

Çalışmada kullanılan yaşam boyu öğrenme eğilimleri ile bireysel yenilikçilik düzeyleri ölçeklerinin alt boyutları arasındaki ilişki incelendiğinde ise, alt boyutlar arasında anlamlı ilişkilerin olduğu belirlenmiştir. Yaşam boyu öğrenme eğilimleri ölçeği motivasyon alt boyutu ile bireysel yenilikçilik düzeyleri ölçeği tüm alt boyut ve toplam puanları arasında düşük düzeyde, pozitif ve anlamlı bir ilişki olduğu tespit edilmiştir. Elde edilen bu bulgu ile yaşam boyu öğrenmeye yönelik motivasyonu artan bireylerin bireysel yenilikçilik düzeylerinin de arttğı sonucuna ulaşılmaktadır. Öğretmen adaylarının yaşam boyu öğrenme eğilimleri ölçeği sebat alt boyutu ile bireysel yenilikçilik düzeyleri ölçeği tüm alt boyut ve toplam puanları arasında düşük düzeyde, negatif ve anlamlı bir ilişki olduğu belirlenmiştir. Elde edilen bu bulgu ile yaşam boyu öğrenmede sebat düzeyi artan bireylerin bireysel yenilikçilik seviyelerinde azalmaya sebep olduğu görülmektedir. Öğretmen adaylarının yaşam boyu öğrenme eğilimleri ölçeği öğrenmeyi düzenleme alt boyutu ile bireysel yenilikçilik düzeyleri ölçeği tüm alt boyut ve toplam puanları arasında orta düzeyde, pozitif ve anlamlı bir ilişki olduğu tespit edilmiştir. Yaşam boyu öğrenme eğilimleri ölçeği merak alt boyutu ile bireysel yenilikçilik düzeyleri ölçeği tüm alt boyut ve toplam puanları arasında ise orta düzeyde, negatif ve anlamlı bir ilişki olduğu belirlenmiştir. ilgili alan yazın incelendiğinde yaşam boyu öğrenme eğilimleri ile bireysel yenilikçilik düzeyleri arasındaki ilişkiyi inceleyen sınırlı sayıda çalışmaya rastlanılmıştır (Kılıç, 2015). Kılıç (2015), öğretmenlerin yaşam boyu öğrenme eğilimleri ile bireysel yenilikçilik düzeyleri arasında anlamlı bir ilişki olmadığını buna karşın her iki ölçeğin alt boyutları arasında anlamlı ilişkilerin bulunduğu sonucuna ulaşmıştir.

\section{5. Öneriler}

Yukarıda belirtilen sonuçlar doğrultusunda bazı önerilere yer verilmiştir:

- Öğretmen adaylarının çoğunluğunun "Sorgulayıcı" kategorisinde yer alması öğretmen adaylarının yeniliklere karşı şüpheci ve olumsuz tutumlarının bir göstergesi sayılabilir. Olumsuz yaklaşımların nedenlerini ortaya çıkarabilecek çeşitli çalışmaların yapılması önerilebilir. 
- Toplumun yönlendirilmesinde rol oynayan öğretmenlerin yaşam boyu öğrenme ve yenilikçilik gibi özelliklere sahip olması son derece önemlidir. Bu nedenle öğretmen adaylarının eğitimleri sürecinde, yenilikçi fikirler üretmelerine olanak sağlayacak çeşitli program ve projeler geliştirililebilir, etkinlikler tasarlanabilir.

- Öğretmen adaylarının yaşam boyu öğrenme ve bireysel yenilikçilik özellikleri üzerinde etkili olabilecek faktörlerle ilgili çalışmalar yapılabilir.

\section{Kaynakça}

Akın Kösterelioğlu, M. ve Demir, F. (2014). Öğretmenlerin bireysel yenilikçilik düzeyinin öğretmen liderliğine etkisi. The Journal of Academic Social Science Studies, 26, 247-256.

Akkoyunlu, B. (2008). Bilgi okuryazarlığı ve Yaşam Boyu Öğrenme. 8th International Educational Technology Conference (IETC2008), 6-9 Mayıs 2008. Anadolu Üniversitesi, Eskişehir.

Akkuş, N. (2008). Yaşam boyu öğrenme becerilerinin göstergesi olarak 2006 PISA sonuçlarının Türkiye açısından değerlendirilmesi. (Yayınlanmamış Yüksek Lisans Tezi). Hacettepe Üniversitesi, Ankara.

Avrupa Birliği Komisyonu. (2006). Recommendation of The European Parliament and of the council on key competences for lifelong learning. Erişim tarihi: 22 Aralık 2017 http://eur-lex.europa.eu/legal-content/EN/TXT/?uri=celex:32006H0962 adresinden alınmıştır.

A World Bank (IBRD). (2003). Lifelong learning in the global knowledge economy: challenges for developing countries: a World Bank report. World Bank, Washington, District of Columbia.

Büyüköztürk, Ş. (2017). Sosyal bilimler için veri analizi el kitabı. Pegem Atf İndeksi, 1-213.

Coolahan, J. (2002). Teacher education and the teaching career in an era of lifelong learning. OECD Education Working Papers, No. 2, OECD Publishing, Paris.

Çuhadar, C., Bülbül, C. ve Ilgaz, G. (2013). Öğretmen adaylarının bireysel yenilikçilik özellikleri ile teknopedagojik eğitim yeterlikleri arasındaki ilişkinin incelenmesi ilköğretim Online 12(3), 797-807.

Davis, B., \& Sumara, D. (1997). Cognition, complexity, and teacher education. Harvard educational review, 67(1), 105-126.

Demirel, M. (2009). Yaşam boyu öğrenmenin anahtarı: öğrenmeyi öğrenme 2. Ulusal Eğitim Psikolojisi Sempozyumu Bildiri Kitabı.

Derrick, M. G. (2003). Creating environments conducive for lifelong learning. New directions for adult and continuing education, 2003(100), 5-18.

De Jesus, S., \& Conboy, J. (2001). A stress management course to prevent teacher distress. International Journal of Educational Management, 15(3), 131-137.

Demirel, Y., ve Seçkin, Ö. G. Z. (2008). Bilgi ve bilgi paylaşımının yenilikçilik üzerine etkileri. Çukurova Üniversitesi Sosyal Bilimler Enstitüsü Dergisi, $17(1)$.

Diker Coşkun, Y. (2009). Üniversite öğrencilerinin yaşam boyu öğrenme eğilimlerinin bazı değişkenler açııından incelenmesi (Yayınlanmamış Doktora Tezi). Hacettepe Üniversitesi, Ankara.

Erdamar, G. (2011). An investigation of student teachers' study strategies with respect to certain variables. Educational Research and Evaluation, 17(2), 69-83.

Evin Gencel, i. (2013). Öğretmen adaylarının yaşam boyu öğrenme yeterliklerine yönelik algıları. Eğitim ve Bilim, 38(170), 237-252.

Güleç, i., Çelik, S., ve Demirhan, B. (2012). What is lifelong learning? An evaluation on definition and scope. Sakarya University Journal of Education, 2(3), 34-48.

Hurt, H. T., Joseph, K., ve Cook, C. D. (1977). Scales for the measurement of innovativeness. human communication research, 4, 58-65.

Incik, E. Y., ve Yelken, Y. Y. (2011). Ilköğretim öğretmen adaylarının yenilikçilik düzeyleri mersin üniversitesi örneği. Eskişehir: Anadolu Üniversitesi.

İzci, E. ve Koç, S. (2012). Öğretmen adaylarının yaşam boyu öğrenmeye ilişkin görüşlerinin değerlendirilmesi. Adıyaman Üniversitesi Sosyal Bilimler Enstitüsü Dergisi, 5(9), 101-114.

Kert, S. B. ve Tekdal, M. (2012). farklı eğitim fakültelerine devam eden bireylerin yenilikçilik algılarının karşılaştrılması. Gaziantep University Journal of Social Sciences, 11(4), 1150-1161.

Kılıç, H. (2015) illköğretim Branş Öğretmenlerinin Bireysel Yenilikçilik Düzeyleri ve Yaşam Boyu Öğrenme Eğilimleri ( Denizli ili Örneği) Yayınlanmamış Yüksek Lisans Tezi). Pamukkale Üniversitesi, Eğitim Bilimleri Enstitüsü, Denizli.

Kılıçer, K. ve Odabaşı F. (2010). Bireysel yenilikçilik ölçeği (BYÖ): Türkçeye uyarlama, geçerlik ve güvenirlik çalışması, Hacettepe Üniversitesi Eğitim Fakültesi Dergisi, 38, 150-164.

Kılıçer, K (2011). Bilgisayar ve öğretim teknolojileri eğitimi öğretmen adaylarının bireysel yenilikçilik profilleri. (Yayınlanmamış Doktora Tezi). Anadolu Üniversitesi, Eskişehir.

Knapper, C. \& Cropley, A. J. (2000). Lifelong Learning in Higher Education . London: Kogan Page.

Köroğlu, A. Y. (2014). Okul öncesi öğretmenlerinin ve öğretmen adaylarının bilişim teknolojileri özyeterlik algıları, teknolojik araç-gereç kullanım tutumları ve bireysel yenilikçilik düzeylerinin incelenmesi. (Yayınlanmamış Yüksek Lisans Tezi). Gazi Üniversitesi, Eğitim Bilimleri Enstitüsü, Ankara.

Kulich, J. (1982). Lifelong education and the universities: A Canadian perspective. International Journal of Lifelong Education, 1(2), 123142. 
Lightfoot, K., \& Brady, E. M. (2005). Transformations through teaching and learning: The story of Maine's Osher Lifelong Learning Institute. Journal of Transformative Education, 3(3), 221-235.

Milli Eğitim Bakanlığı Talim ve Terbiye Kurulu Başkanlığı, (2017). İlköğretim Fen ve Teknoloji Dersi (6, 7, 8. Sınıflar) Öğretim Programı. M.E.B. Ankara.

Nijhof, W. J. (2005). Lifelong learning as a European skill formation policy. Human Resource Development Review, 4(4), $401-417$.

OECD. (1996). The Knowledge Based Economy, General Distribution OCDE/ GD(96) 102, Paris.

Ozan, C., Çelik, N. ve Kıncal, R. Y. (2014). Öz-düzenlemeli öğrenme öğretmen inanç ölçeğinin dilsel eşdeğerlik, geçerlik ve güvenirlik çalışması.1. Avrasya Eğitim Araştırmaları Kongresi, İstanbul.

Özgür, H. (2013). Bilişim teknolojileri öğretmen adaylarının eleştirel düşünme eğilimleri ile bireysel yenilikçilik özellikleri arasındaki ilişkinin çeşitli değişkenler açısından incelenmesi. Mersin Üniversitesi Eğitim Fakültesi Dergisi, 9(2), 409-420.

Partnership for 21st century skills. (2010). 21st Century Knowledge And Skills In Educator Preparation Erişim Tarihi:21 Aralık 2010 http:// www.p21.org/storage/documents/aacte_p21_whitepaper2010.pdf

Piaget, J. (1952). Introduction à l'épistémologie génétique. T. I: La pensée mathématique.

Rogers, E.M. (1995). Diffusion of innovations (Third Edition). New York: Free Press.

Senemoğlu, N. (2009). Gelişim öğrenme ve öğretim kuramdan uygulamaya. Geliştirilmiş 14.Baskı. Ankara: Pegem Akademi.

Şahin, Ç. ve Arcagök, S. (2014). Öğretmenlerin yaşam boyu öğrenme yeterlikleri düzeyinin çeşitli değişkenler açısından incelenmesi Adıyaman Üniversitesi Sosyal Bilimler Enstitüsü Dergisi, 7(16), 394-417.

De Tarde, G. (1903). The laws of imitation. H. Holt.

Timuçin, M. (2009). Diffusion of technological innovat ion in a foreign languages unit in Turkey: A focus on risk-aversive teachers. Technology, Pedagogy and Education, 18(1), 75-86.

Türk Dil Kurumu (TDK). (2014). Türkçe Sözlük. Erişim: http://www.tdk.gov.tr

UNESCO (1996). Information And Communication Technologies In Teacher Education a Planning Guide.

Ünal, H.(2014). Üniversite öğrencilerinin bireysel yenilikçilik kategorilerinin belirlenmesi. Uluslararası Hakemli Akademik Spor Sağlık ve Tıp Bilimleri Dergisi. 4(11),68-74.

White, R. (1998). The ELT Curriculum: Design, Innovation and Mangement. Wiley-Blackwell.

Yavuz Konokman, G. ve Yanpar Yelken, T. (2014). Eğitim fakültesi öğretim elemanlarının yaşam boyu öğrenme yeterliklerine ilişkin algıları. Hacettepe Üniversitesi Eğitim Fakültesi Dergisi, 29, 267-281.

Yenilmez, K., ve Balbağ, M. Z. (2016). Fen bilgisi ve ilköğretim matematik öğretmeni adaylarının STEM'e yönelik tutumları. Journal of Research in Education and Teaching, 5(4), 301-307.

Yılmaz Öztürk, Z.ve Summak M.S. (2014). Ilköğretim okulu öğretmenlerinin bireysel yenilikçiliklerinin incelenmesi. International Journal of Science Culture and Sport doi: 10.14486/IJSCS158.

Yılmaz, N. (2013). Okul öncesi öğretmen adaylarının bireysel yenilikçilik düzeyleri ve öğretim amaçlı bilgisayar kullanımına yönelik algıIanan özelliklerin araştırılması. (Yayınlanmamış Yüksek Lisans Tezi). Ortadoğu Teknik Üniversitesi, Sosyal Bilimler Enstitüsü, Ankara. 